\title{
Sweet spot prediction in tight sandstone reservoir based on well-bore rock physical simulation
}

\author{
Hai-ting Zhou ${ }^{1,3} \cdot$ De-yong $\mathrm{Li}^{2,4,5} \cdot$ Xian-tai Liu ${ }^{1} \cdot$ Yu-shan Du ${ }^{1} \cdot$ Wei Gong ${ }^{4,5}$
}

Received: 9 June 2018 / Published online: 31 October 2019

(c) The Author(s) 2019

\begin{abstract}
To establish the relationship among reservoir characteristics and rock physical parameters, we construct the well-bore rock physical models firstly, considering the influence factors, such as mineral composition, shale content, porosity, fluid type and saturation. Then with analyzing the change rules of elastic parameters along with the above influence factors and the cross-plots among elastic parameters, the sensitive elastic parameters of tight sandstone reservoir are determined, and the rock physics template of sweet spot is constructed to guide pre-stack seismic inversion. The results show that velocity ratio and Poisson impedance are the most sensitive elastic parameters to indicate the lithologic and gas-bearing properties of sweet spot in tight sandstone reservoir. The high-quality sweet spot is characterized by the lower velocity ratio and Poisson impedance. Finally, the actual seismic data are selected to predict the sweet spots in tight sandstone gas reservoirs, so as to verify the validity of the rock physical simulation results. The significant consistency between the relative logging curves and inversion results in different wells implies that the utilization of well-bore rock physical simulation can guide the prediction of sweet spot in tight sandstone gas reservoirs.
\end{abstract}

Keywords Tight sandstone reservoir $\cdot$ Sweet spot $\cdot$ Sensitive elastic parameter $\cdot$ Well-bore rock physical simulation $\cdot$ Rock physics template $\cdot$ Pre-stack seismic inversion

\section{Introduction}

Edited by Xiu-Qiu Peng

De-yong Li

ldyc411@ouc.edu.cn

1 Exploration and Development Institute of Shengli Oilfield, Dongying 257100, China

2 Shandong Provincial Key Laboratory of Depositional Mineralization and Sedimentary Minerals, Shandong University of Science and Technology, Qingdao 266590, Shandong, China

3 Postdoctoral Scientific Research Workstation of Sinopec Shengli Oilfield, Dongying 257100, China

4 Key Laboratory of Submarine Geosciences and Prospecting Techniques, MOE, College of Marine Geosciences, Ocean University of China, Qingdao 266100, China

5 Evaluation and Detection Technology Laboratory for Marine Mineral Resources, Qingdao National Laboratory for Marine Science and Technology, Qingdao 266100, China
Although conventional reservoirs remain a very important part of the world's oil and gas supply, horizontal drilling and multistage fracturing have now made it possible to exploit and develop unconventional reservoirs (Sharma and Chopra 2016). Recently, the tight sandstone gas reservoir is one of the most important exploration and development targets of unconventional reservoirs in China. And the tight sandstone gas has become the most promising energy in the natural gas resource field, with 39\% of total gas reserves and 25\% of total gas production (Zou et al. 2016; Dai et al. 2017). It is a fact that the prediction of the effective reservoirs rich in gas resources is the key issue to the exploration of the tight sandstone gas reservoirs (Hart 2008; Albrecht and Reitenbach 2014). The effective gas reservoirs with relatively high porosity and permeability, which develop in the large-scale tight sandstone, can be defined as sweet spot of tight sandstone reservoir (Yang et al. 2013; Cudjoe et al. 2016). At present, the techniques such as facies-controlled modeling, seismic inversion, are used to realize the reservoir description and fluid prediction (He et al. 2011; Amiri et al. 2015; 
Zheng et al. 2018; Qian et al. 2019). But for tight sandstone reservoir, the impedance difference between sweet spots and adjacent formations is small, and pure post-stack seismic inversion cannot fully meet the needs of these predictions and descriptions. As a consequence, the pre-stack seismic inversion, which can reveal the reservoir petro-physical characteristics, has been widely used to predict the sweet spots of tight sandstone reservoir (Chen et al. 2009; Bosch et al. 2010; Zong et al. 2016; Zhang et al. 2017a, b).

Recent advances in pre-stack seismic data analysis show that some elastic parameters appear to be correlated with formation lithology, porosity and pore fluid (Sena et al. 2011; Zhang et al. 2012a, b). Accordingly, these parameters can yet be regarded as effective factors to predict sweet spots. However, constrained by the complexity and variability of reservoirs, the elastic parameters of different reservoirs often have some range of overlap (Bachrach 2006; Sengupta and Bachrach 2007), and the variance caused by the analysis of elastic parameters may lead to further error in inversion of sweet spot. Thus, to improve the accuracy in predicting the sweet spot of tight sandstone reservoir, it is essential to build up the relationship between the elastic and petro-physical characteristics of tight sandstone reservoir and determine the sensitive elastic parameters for lithology, porosity and pore fluid of sweet spot. Based on the P-wave velocity, S-wave velocity and bulk density from well logs and rock test data, the reservoir petro-physical properties can be extended to seismic attributes, so as to understand the elastic modulus in relation to five constituents: lithology, porosity, permeability, fluid type and saturation (Berryman et al. 2002; Khalid and Ghazi 2013; Khalid et al. 2014; Ahmed et al. 2015), and find the most sensitive hydrocarbon indicators to pore fluid (Feng et al. 2007). We have to admit that the method to determine the best indicator using well logs and rock test data is not suitable for the area with little or no wells, and the best indicator needs to be calibrated and tested for the local situation (Chen et al. 2009). Seismic rock physical analysis is an important technique to establish the connection between reservoir elastic parameters and petro-physical properties in the research area with little and no wells (Mollajan et al. 2015; Ahmed et al. 2016; Ehsan et al. 2016).

So, the well-bore rock physical simulation of sweet spot of tight sandstone reservoir was carried out in this paper. With analyzing the differences among sweet spot, tight sandstone and mudstone, and the variation of elastic parameters of different sweet spots, the main purpose of this paper is to determine the sensitive elastic parameters for lithology, porosity and fluid saturation of sweet spot, respectively, and establish the physical recognition template of sweet spot. Eventually, the technologies of rock physics analysis and pre-stack elastic parameters inversion were perfectly combined to predict the sweet spot of tight sandstone reservoir in a case study.

\section{Well-bore rock physical simulation}

\subsection{Forward simulation research idea}

Actually, reservoir rock is a saturated porous medium consisting of solid matrix and pore fluids with heterogeneity and anisotropy properties, which lead to the complexity of the seismic wave propagation process. In order to simulate the velocity characteristics of the rock, the rock is usually described as an equivalent body, which is simplified as a two-phase medium.

Utilizing rock physical test results and well-logging data of research area, solid models and pore-fluid models are built after supposing parameters such as mineral components, porosity, pore-fluid type and saturation. Then, well-bore reservoir models with different research targets can be constructed by different combinations of solid models and pore-fluid models. On this basis, the velocities and densities of wellbore reservoirs are simulated utilizing difference rock physical simulation equations (Shuey 1985; Hyndman and Spence 1992; Jakobsen et al. 2000) and the Gassmann's poroelastic model (Gassmann 1951). For theoretical well-bore reservoir models, the elastic parameters are calculated with the simulation of P-wave velocity, S-wave velocity and density firstly, and then the sensitive elastic parameters of sweet spot for lithology prediction and fluid identification can be determined with analyzing the variation rules of elastic parameters changing with the reservoir petro-physical properties. On this basis, the rock physical template of sweet spot is built. For actual wellbore reservoir models lacking S-wave velocity, genetic algorithm method is introduced into simulation process. By comparing the P-wave velocity and bulk density of well-logging data with corresponding simulation results, mineral model of actual well-bore reservoir model is adjusted constantly using genetic algorithm method. When the error between measured and simulated results satisfies certain conditions, the currently $\mathrm{S}$-wave velocity is the prediction result. Finally, combined with $\mathrm{S}$-wave velocity prediction results and rock physical template, the sweet spot of tight sandstone reservoir can be predicted with the help of pre-stack seismic inversion (Fig. 1).

\subsection{Forward principle and method}

After Khalid et al. (2015), the Gassmann's relation can be represented in the following form as:

$K_{\mathrm{sat}}=K_{\mathrm{dry}}+\left[1-\frac{K_{\mathrm{dry}}}{K_{\mathrm{ma}}}\right]^{2} /\left[\frac{\phi}{K_{\mathrm{fl}}}+\frac{1-\phi}{K_{\mathrm{ma}}}-\frac{K_{\mathrm{dry}}}{K_{\mathrm{ma}}^{2}}\right]$

where $\phi$ is the reservoir porosity. Since the effective shear modulus $\left(\mu_{\text {sat }}\right)$ is not affected by the nature and amount of pore fluids, Gassmann's model assumes:

$\mu_{\mathrm{sat}}=\mu_{\mathrm{dry}}$ 


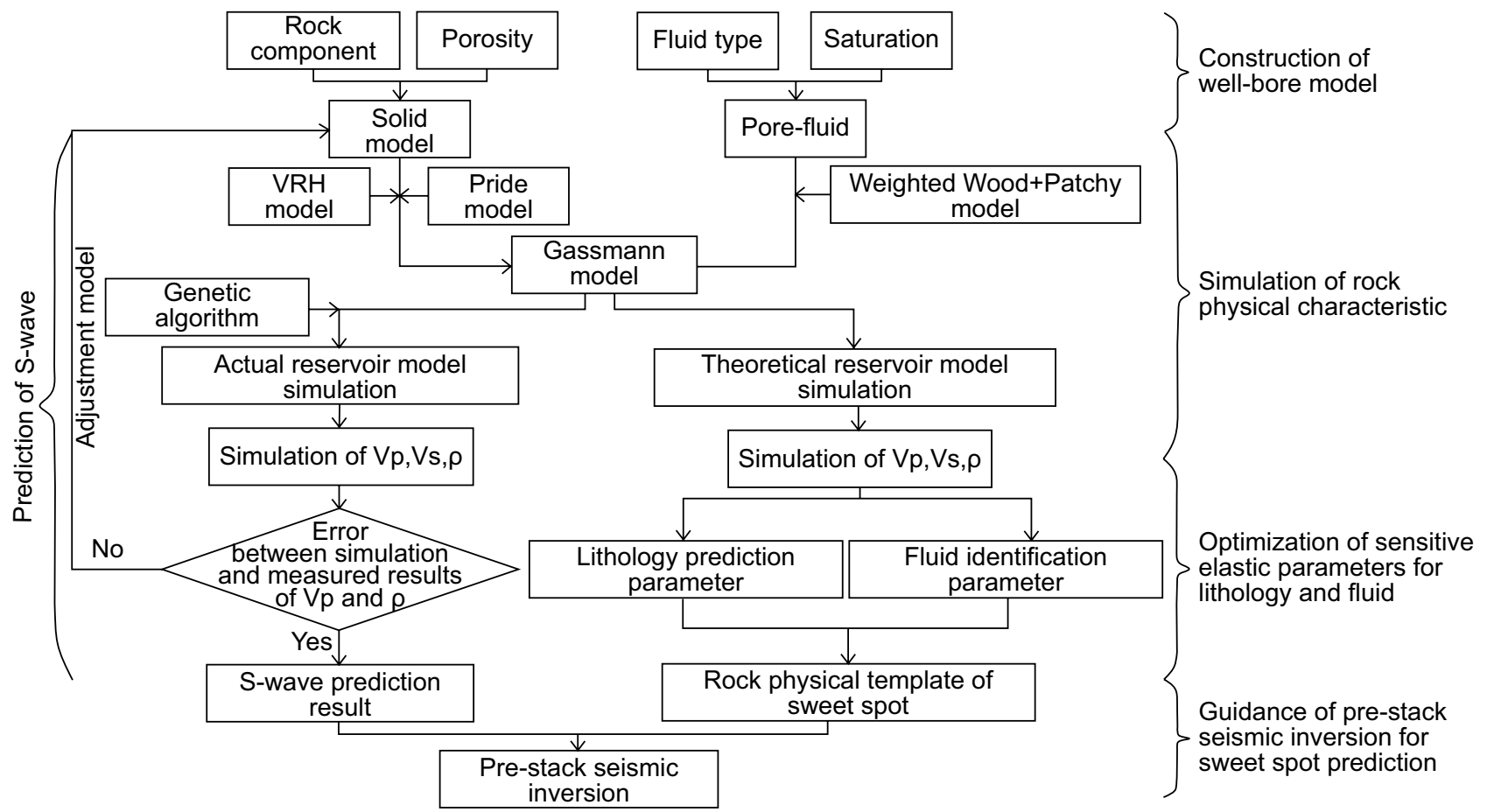

Fig. 1 Research idea for sweet spot prediction based on well-bore rock physical simulation

here $\mu_{\mathrm{dry}}$ is the shear modulus of rock frame.

The above Gassmann relation is used to simulate the physical characteristics of the rock with completely saturated single-phase fluid. While as the tight sandstone, its pore spaces usually contain two or more phase fluids, and the pore fluids may be unsaturated. So an equivalent volume modulus formula for partially saturated mixed fluids should be introduced into Gassmann relation so as to simulate the physical characteristic of tight sandstone (Wang 2016; Si et al. 2017). Usually, the $K_{\mathrm{fl}}$ of pore fluids is determined by Wood's average relation, but Mavko and Mukerji (1998) pointed out that partial pore filling is not complete in the case of low porosity of rocks, which will reduce the applicability of Wood model. So the weighted Wood and Patchy model is used to calculate the $K_{\mathrm{fl}}$ of the tight sandstone reservoir in this paper.

$K_{\mathrm{fl}}=a \times K_{\text {Patchy }}+b \times K_{\text {Wood }}$

where $K_{\text {Patchy }}$ and $K_{\text {Wood }}$ are the bulk modulus of pore fluids calculated by Patchy relation and Wood relation, respectively. $a$ and $b$ are weighted coefficients, and $a+b=1$.

As the important intermediate parameters to obtain the modulus of fluid saturated rock, the $K_{\text {dry }}$ and $\mu_{\text {dry }}$ of drained rock should be calculated. At present, there are several methods to calculate the modulus of drained rock (Berryman 1995; $\mathrm{Xu}$ and White 1995; Lee 2006). Due to the low degree of research on deep tight sandstone reservoir in the East China Sea Shelf Basin, the pore structure data of tight sandstone in this basin are not perfect, which lead to the difficult application of Xu-White model. In this paper, we used the revised Pride experience model (Pride et al. 2004) with the following expressions:

$K_{\text {dry }}=\frac{K_{\mathrm{ma}}(1-\phi)}{(1+c \phi)}$

$\mu_{\mathrm{dry}}=\frac{\mu_{\mathrm{ma}}(1-\phi)}{(1+\gamma c \phi)}$

The parameter $c$ is named rock consolidation parameter, and $\gamma$ is an adjusting parameter, calculated by the relation: $\gamma=(1+2 c) /(1+c)$. The value of $\mathrm{c}$ is related to the pore shape and the ratio of bulk and shear modulus of solid matrix, which can reflect the pore structure to some extent (Pride 2005). By comparing the elastic curves calculated by different rock consolidation parameters and the rock physical test results of drained sandstones, we can get the best rock consolidation parameter suitable for the research area.

The elastic modulus of solid matrix is calculated by the corresponding modulus of each mineral in the rock, using VRH average model.

$M_{\mathrm{ma}}=\left(\sum_{i=1}^{N} f_{i} M_{i}+1 / \sum_{i=1}^{N} \frac{f_{i}}{M_{i}}\right) / 2$ 
where $M_{i}$ is the elastic modulus of single mineral (mainly represents bulk and shear modulus in this paper) and $f_{i}$ is the content of the mineral.

Based on the modified Gassmann relation, the P-wave and $\mathrm{S}$-wave velocity of tight sandstone can be calculated using the relations as follows:

$V_{p}=\sqrt{\left(K_{\mathrm{sat}}+\frac{4}{3} \mu_{\mathrm{sat}}\right) / \rho_{\mathrm{sat}}}$

$V_{s}=\sqrt{\mu_{\text {sat }} / \rho_{\text {sat }}}$

where the bulk density $\left(\rho_{\text {sat }}\right)$ of fluid saturated rock as a function of porosity $(\phi)$, fluid $\left(\rho_{\mathrm{ff}}\right)$ and matrix $\left(\rho_{\text {ma }}\right)$ density is given:

$\rho_{\mathrm{sat}}=\rho_{\mathrm{ma}}+\phi \rho_{\mathrm{fl}}=\sum_{i=1}^{N} f_{i} \rho_{i}+\phi\left(S_{\mathrm{water}} \rho_{\mathrm{water}}+S_{\mathrm{gas}} \rho_{\mathrm{gas}}\right)$

where $\rho_{i}$ is the density of single mineral, $f_{i}$ is the content of the mineral, $S_{\text {water }}$ is the saturation of brine, $S_{\text {gas }}$ is the saturation of gas, $\rho_{\text {water }}$ is the density of brine, and $\rho_{\text {gas }}$ is the density of gas.

The above relations are used to simulate the effect of pore fluids on seismic response where various parameters (e.g., the bulk and shear modulus of minerals, the bulk modulus of fluids, the densities of minerals and fluids and porosity, saturation of brine and gas) are mandatory. The modulus and density of rock component are mostly measured in the laboratory, and the content can be supposed during the simulation process. According to the Mineral Handbook of Schlumberger and Ahmed et al. (2016), parts of inputs are given in Table 1:
Mineral content, porosity and water saturation are the important parameters to reflect the physical properties of reservoir rock. To determine the sensitive elastic parameters of sweet spot of tight sandstone reservoir, mudstone model, tight sandstone model, water-bearing sandstone model and sweet spot model are supposed in this paper where the corresponding physical parameters are obtained from rock test results and well-logging data of research area, and detailed values are shown in Table 2:

\subsection{Analysis of simulation results and optimization of sensitive elastic parameters}

Aiming at predicting the sweet spot of tight sandstone reservoir, a technological process of successive approximation, which is from lithology prediction to physical property prediction to gas-bearing prediction, has been designed. Firstly, the sandstone reservoir (lithologic model) is predicted from clastic rocks, then the relatively high porosity and permeability reservoir (physical model) is searched from tight sandstone, and finally the high-quality reservoir (gas-bearing model) is predicted. Based on this deepening process, three theoretical well-bore reservoir models with different research targets are built based on the four constructed rock models. Model a is used to select the elastic parameters which can reveal the change of lithology by altering the shale content mainly. Model $b$ mainly changes porosity so as to choose the elastic parameters sensitive to the physical characteristics of tight sandstone. With changing the water saturation, model $\mathrm{c}$ can tell us the sensitive elastic parameters of gas-bearing properties (Fig. 2). After constructing well-bore reservoir physical models, the elastic parameters can be calculated using the above method and

Table 1 Bulk and shear modulus and densities of minerals and fluids used in Gassmann's poroelastic model

\begin{tabular}{llllllll}
\hline Rock component & Quartz & $\begin{array}{l}\text { Potassium feld- } \\
\text { spar }\end{array}$ & Anorthose & Calcite & Clay & Brine & Gas \\
\hline$K, \mathrm{GPa}$ & 37.8 & 45.8 & 75.6 & 76.2 & 25.0 & 3.16 \\
$\mu, \mathrm{GPa}$ & 44.4 & 27.8 & 25.6 & 30.3 & 18.5 & - \\
$\rho, \mathrm{g} / \mathrm{cm}^{3}$ & 2.65 & 2.57 & 2.61 & 2.71 & 2.5 & 1.178 \\
\hline
\end{tabular}

Table 2 Mineral content, porosity and water saturation of the five rock physical models

\begin{tabular}{llllllll}
\hline Rock physical model & \multicolumn{2}{l}{ Mineral content, $\%$} & & Porosity, $\%$ & Water saturation, $\%$ \\
\cline { 2 - 6 } & Quartz & $\begin{array}{l}\text { Potassium } \\
\text { feldspar }\end{array}$ & Anorthose & Calcite & Clay & \\
\hline Mudstone & 4.5 & 2.0 & 2.5 & 1.0 & 90 & 0 & 100 \\
Tight sandstone & $61.6-79.6$ & 4.2 & 6.5 & 3.7 & $5-20$ & $1-4$ & $0-100$ \\
Water-bearing sandstone & $61.6-79.6$ & 4.2 & 6.5 & 3.7 & $5-20$ & $6-14$ & $60-100$ \\
Sweet spot & $61.6-79.6$ & 4.2 & 6.5 & 3.7 & $5-20$ & $6-14$ & $0-60$ \\
\hline
\end{tabular}


data. At present, there are various elastic parameters and corresponding combination parameters; in this paper, we mainly choose $\mathrm{P}$-wave impedance (AI), S-wave impedance (SI), velocity ratio $\left(V_{p} / V_{s}\right)$, shear modulus $(\mu)$, bulk modulus $(K)$, lame constant $(\lambda)$, Poisson impedance (PI) and fluid factor $(F)$ (Table 3).
From the simulation results of model a, velocity ratio, lame constant, Poisson impedance and fluid factor change regularly with shale content alteration; the values of these elastic parameters decrease with the decrease in shale content (Fig. 2a). Comparing the elastic parameter curves of pure gas sandstone and pure water sandstone with different

\begin{tabular}{|c|c|c|c|c|c|c|c|c|c|c|c|}
\hline \multicolumn{4}{|c|}{ Wellbore forward model } & \multicolumn{8}{|c|}{ Comparison of simulation curves } \\
\hline Lithology & $\begin{array}{c}\text { vsh, } \\
\%\end{array}$ & $\begin{array}{l}\text { por, } \\
\%\end{array}$ & $\begin{array}{l}\text { Sw, } \\
\%\end{array}$ & \begin{tabular}{|c|}
$5-20$ \\
$\times 10^{3}$
\end{tabular} & 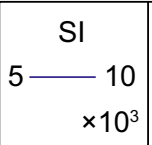 & $\begin{array}{c}\mathrm{Vp} / \mathrm{Vs} \\
1.5-2.0\end{array}$ & $\begin{array}{r}\mu \\
10-30 \\
\quad \times 10^{6}\end{array}$ & $\begin{array}{r}\mathrm{K} \\
\\
\quad 40 \\
\times 10^{6}\end{array}$ & 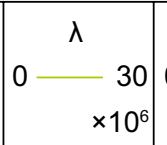 & \begin{tabular}{|l}
$\mathrm{PI}$ \\
0 \\
$\quad$ \\
$\quad \times 10^{3}$
\end{tabular} & $\begin{array}{r}\mathrm{F} \\
0-50 \\
\times 10^{6}\end{array}$ \\
\hline $1^{--}$ & 90 & 0 & 100 & & & & & & & & \\
\hline II $\bullet \bullet$ & 20 & 3 & 100 & & & & & & & & \\
\hline II $\bullet \bullet$ & 15 & 3 & 100 & & & & & & & & \\
\hline${ }_{\mathrm{II}} \bullet \bullet$ & 10 & 3 & 100 & & & & & & & & \\
\hline II $\bullet \bullet$ & 5 & 3 & 100 & & & & & & & & (a) \\
\hline $1^{--}$ & 90 & 0 & 100 & & & & & & & & \\
\hline IIII $\bullet$ & 10 & 4 & $0 / 10 c$ & & & & & & & & \\
\hline III $\bullet \bullet$ & 10 & 7 & $0 / 100$ & & & 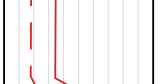 & & & | & & 1 \\
\hline III $\bullet \bullet$ & 10 & 10 & $0 / 100$ & 1 & & 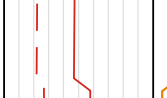 & & $\begin{array}{l}1 \\
1\end{array}$ & 1 & & 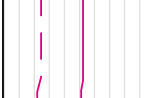 \\
\hline III $\bullet \bullet$ & 10 & 13 & $0 / 100$ & 1 & & 1 & & $\begin{array}{l}1 \\
1\end{array}$ & 1 & 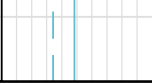 & 1 \\
\hline-- & 90 & 0 & 100 & & & & & & & & \\
\hline IV & 10 & $6 / 12$ & 0 & | & | & & & & & & \\
\hline IV & 10 & $6 / 12$ & 30 & ! & 1 & 1 & 1 & 1 & & & \\
\hline V & 10 & $6 / 12$ & 70 & ! & | & 1 & | & 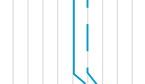 & & & \\
\hline V & 10 & $6 / 12$ & 100 & 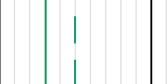 & 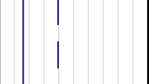 & 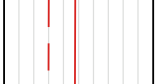 & 1 & & & & ) \\
\hline
\end{tabular}

Fig. 2 The elastic parameter simulation curves of lithologic well-bore rock physical model (a), porosity well-bore rock physical model (b) and fluidic well-bore rock physical model (c) 
Table 3 Calculation equations of elastic parameters used in the article (Russell et al. 2003; Quakenbush et al. 2006; Pei et al. 2010; Yin et al. 2015)

\begin{tabular}{llll}
\hline Elastic parameter & Formulas & Elastic parameter & Formulas \\
\hline P-wave impedance & $\mathrm{AI}=\rho * V_{p}$ & S-wave impedance & $\mathrm{SI}=\rho^{*} V_{s}$ \\
Velocity ratio & $\gamma=V_{p} / V_{s}$ & Shear modulus & $\mu=\rho * V_{s}^{2}$ \\
Bulk modulus & $K=\rho *\left(V_{p}^{2}-4 / 3 * V_{s}^{2}\right)$ & Lame constant & $\lambda=\rho *\left(V_{p}^{2}-2 * V_{s}^{2}\right)$ \\
Poisson impedance & $\mathrm{PI}=\mathrm{AI}-c \mathrm{SI}$ & Fluid factor & $F=\mathrm{AI}^{2}-b \mathrm{SI}^{2}$ \\
\hline
\end{tabular}

porosity, we can see that: only S-wave impedance and shear modulus are not affected by the change of pore fluid basically, presented as the decrease in S-wave impedance and shear modulus vary with the increase in porosity (Fig. 2b). For the sandstones with different water saturation, most of elastic parameters except S-wave impedance and shear modulus perform as regularly variation with water saturation on the condition of same porosity. But comparing the elastic parameter curves of well-bore reservoir models with same water saturation and different porosity, only lame constant, Poisson impedance and fluid factor are not affected by the change of porosity (Fig. 2c). According to the theoretical well-bore simulation results, velocity ratio, S-wave impedance, lame constant, Poisson impedance and fluid factor may be the sensitive elastic parameters to identify the sweet spot.

From I to $\mathrm{V}$ are represented as different rock models, I is mudstone model, II are tight sandstone models with different shale content, III are effective sandstone models with different porosity (dotted line indicates pure gas sandstone $S w=0 \%$; solid line indicates pure water sandstone $S w=100 \%$ ), IV and V are sweet spot models and waterbearing models, respectively, with different saturation (dotted line indicates sandstone with $6 \%$ porosity; solid line indicates sandstone with $12 \%$ porosity). The detail mineral content of every rock models is supposed in Table 2.

In order to further discuss the validity of the above elastic parameters, which have been determined through the theoretical well-bore rock physical simulation, the change rules of the elastic parameters with the alteration of shale content, porosity and water saturation have been verified. Velocity ratio of sandstone increases varies with the increase in shale content, porosity and water saturation, but the controlling factors affecting velocity ratio of sandstone are different with the difference of porosity. For the sandstone with low porosity $(<10 \%)$, velocity ratio is mainly affected by shale content and porosity, while for the high-porosity ( $>14 \%$ ) sandstone, the influence of water saturation on velocity ratio is increasing; particularly for the high-porosity sandstone with water saturation bigger than $90 \%$, its velocity ratio has been higher than mudstone (Fig. 3a). However, on the condition of actual geological conditions, velocity ratio can distinguish most of sandstones and mudstones. The main affecting factor of $\mathrm{S}$-wave impedance and shear modulus is porosity, shown as the decrease with the increase in porosity, and when the porosity increases to a certain extent, the S-wave impedance and shear modulus tend to be stable. Comparing the variation of S-wave impedance and shear modulus vary with water saturation under the same porosity condition, S-wave impedance of sandstone with high porosity is influenced by the fluid properties more obviously, its value increases slowly with the increased water saturation (Fig. 3b), while shear modulus is almost impervious to pore fluid (Fig. 3c). Lame constant, Poisson impedance and fluid factor are commonly used for fluid prediction, but lame constant and fluid factor increase first and then decrease with the increase in porosity, which indicate that the lame constant and fluid factor of tight sandstone will overlap with low porosity reservoir, and with the increase in water saturation, the overlap range is becoming wider (Fig. 3d, e). At the same condition, the overlap problem of Poisson impedance will occur when the water saturation of tight sandstone is bigger than $80 \%$. For most tight sandstone reservoirs, Poisson impedance decreases with the increase in porosity and the decrease in water saturation obviously, the low Poisson impedance maybe indicated the high quantity reservoir. And compared with lame constant and fluid factor, Poisson impedance is less affected by shale content (Fig. 3f).

From the above theoretical well-bore rock physical simulation results, it is denoted that velocity ratio can distinguish most of sandstones and mudstones on the actual geological conditions, low velocity ratio reflects the pure tight sandstone. Shear modulus is a good indicator to reflect the physical properties of sandstone, but when the porosity of sandstone is large, the shear modulus tends to be stable and the recognition effect of physical properties begins to weaken. Poisson impedance changes regularly with porosity and water saturation, and the low PI indicates high-quality reservoir with the high porosity and gas saturation.

\section{The rock physics template of sweet spot}

Usually, the elastic parameters of sweet spot are influenced by multi-geophysical properties, and it's difficult to predict and describe the sweet spot distribution precisely just using single elastic parameter. The target of the interaction 

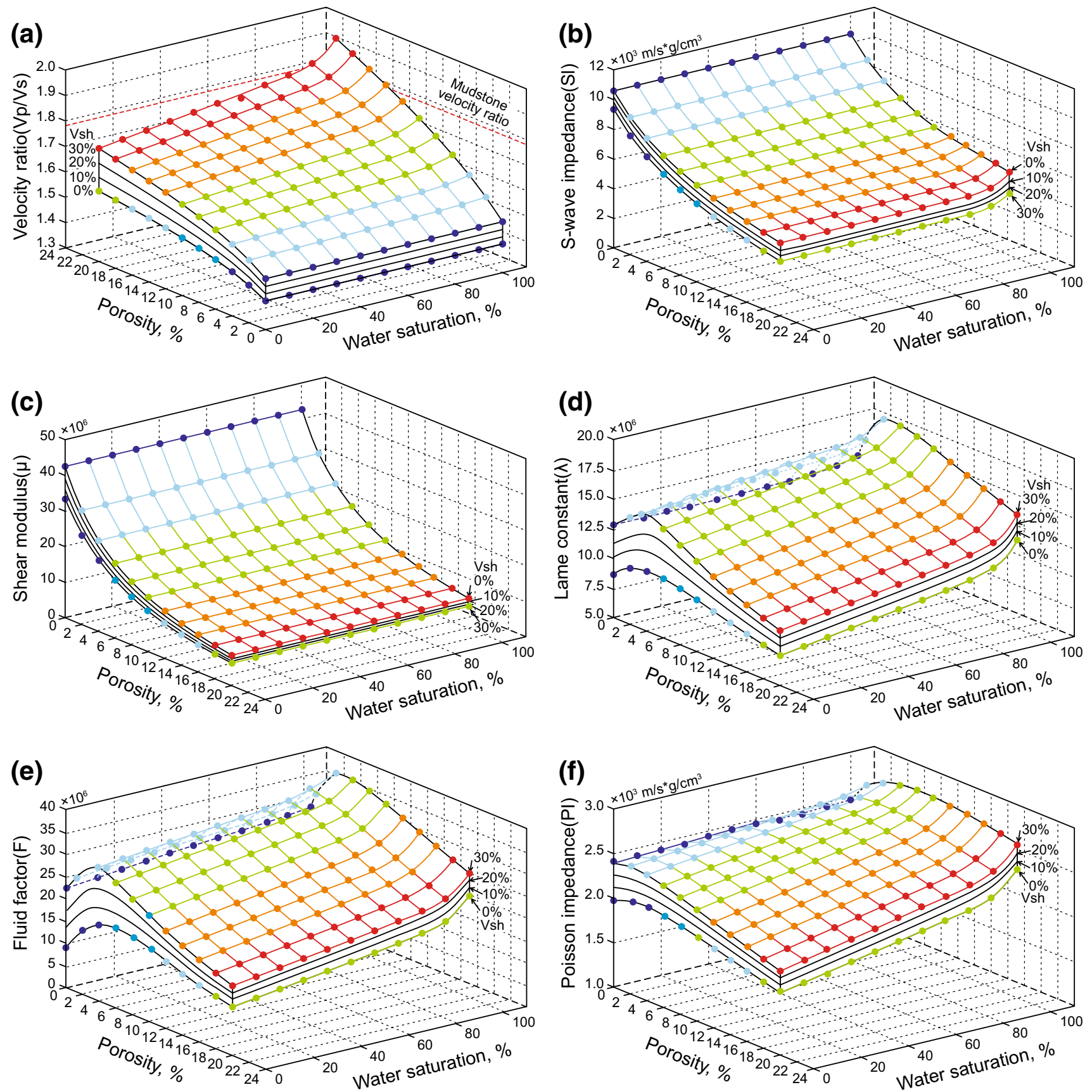

Fig. 3 Change rules of the velocity ratio (a), S-wave impedance (b), shear modulus (c), lame constant (d), Poisson impedance (e) and fluid factor (f) vary with the alteration of shale content, porosity and water saturation

analysis among elastic parameters is to build up the relationship between elastic parameters and reservoir geophysical properties. With the optimization of the best indicators for the lithology and fluid characteristics of sweet spot, the rock physics template of reservoir can be constructed, so as to determine the elastic criterion for the sweet spot prediction.

According to the elastic parameters' change rules, there is a preliminary conclusion that velocity ratio, shear modulus and Poisson impedance can reflect the changes of lithology, porosity and pore fluid among different rocks, respectively. But we note that the variation of porosity can be revealed by Poisson impedance, and the reservoir with high porosity is characterized by the low Poisson impedance. So the cross-plot between velocity ratio and Poisson impedance is mainly painted in this paper. Under the same shale content, sweet spot and water-bearing sandstone can be distinguished obviously using velocity ratio and Poisson impedance, and the elastic characters of sweet spot show low velocity ratio 
and Poisson impedance. The contrast between sweet spot and tight sandstone with the similar mineral content implies that the velocity ratio of sweet spot is higher than that of tight sandstone, while the Poisson impedance of sweet spot is lower than that of tight sandstone. Although the velocity ratio of sweet spot increases with the shale content, it is still lower than the velocity ratio of mudstone with the value reaching to 1.77 (Fig. 4). We can use velocity ratio and Poisson impedance to distinguish sweet spot from tight sandstone, water-bearing sandstone and mudstone effectively. Thus, velocity ratio and Poisson impedance are utilized to construct the rock physics template of sweet spot in this article.

On the basis of the construction of rock physics template of sweet spot, the actual data, which are calculated from well-logging data, are projected onto the template (Fig. 4). The result shows that the mudstone, tight sandstone and water-bearing sandstone are mainly concentrated in the area with high velocity ratio and Poisson impedance, and the elastic property of sweet spot is characterized by low velocity ratio and Poisson impedance. As can be noticed, the elastic parameters of tight sandstone, sweet spot and waterbearing sandstone are overlap, but we can identify most of sweet spots using velocity ratio and Poisson impedance.

In general, velocity ratio and Poisson impedance are the most sensitive elastic parameters for the prediction of sweet spot. Velocity ratio is the best lithologic indicator to distinguish sandstone and mudstone. On the basis of the prediction of sandstone, Poisson impedance can reflect the distribution of natural gas bearing in the reservoir with high porosity effectively. For the research area, the range of velocity ratio of sandstone is about $1.5-1.65$, and the Poisson impedance of gas-bearing reservoir is probably less than $2100 \mathrm{~m} / \mathrm{s} \mathrm{g} / \mathrm{cm}^{3}$. Under the guidance of the above elastic criterion, the pre-stack seismic inversion can be carried out to predict the sweet spot.

\section{Application effects of forward simulation and discussions}

\subsection{Reservoir characteristic of test area}

The test area is located in a basin in the East China Sea. The buried depth of the target layers is generally over $3500 \mathrm{~m}$, with the formation pressure between 34 and $62 \mathrm{MPa}$, and the formation temperature between 142 and $170{ }^{\circ} \mathrm{C}$, belongs to the deep clastic rock tight reservoir with high temperature and pressure. As the target layers in this paper, the single sand body of layer A and B is thick and may be the potential strata with a high-quality reservoir (Fig. 5a). Indicated by the statistical results of the core porosity and permeability in different wells, it can be seen that the difference in core porosity between A and B layers is not significant, the variation range of core porosity in A layer is about $6 \%-15 \%$, and that in B layer is about $4 \%-14 \%$. But the difference in

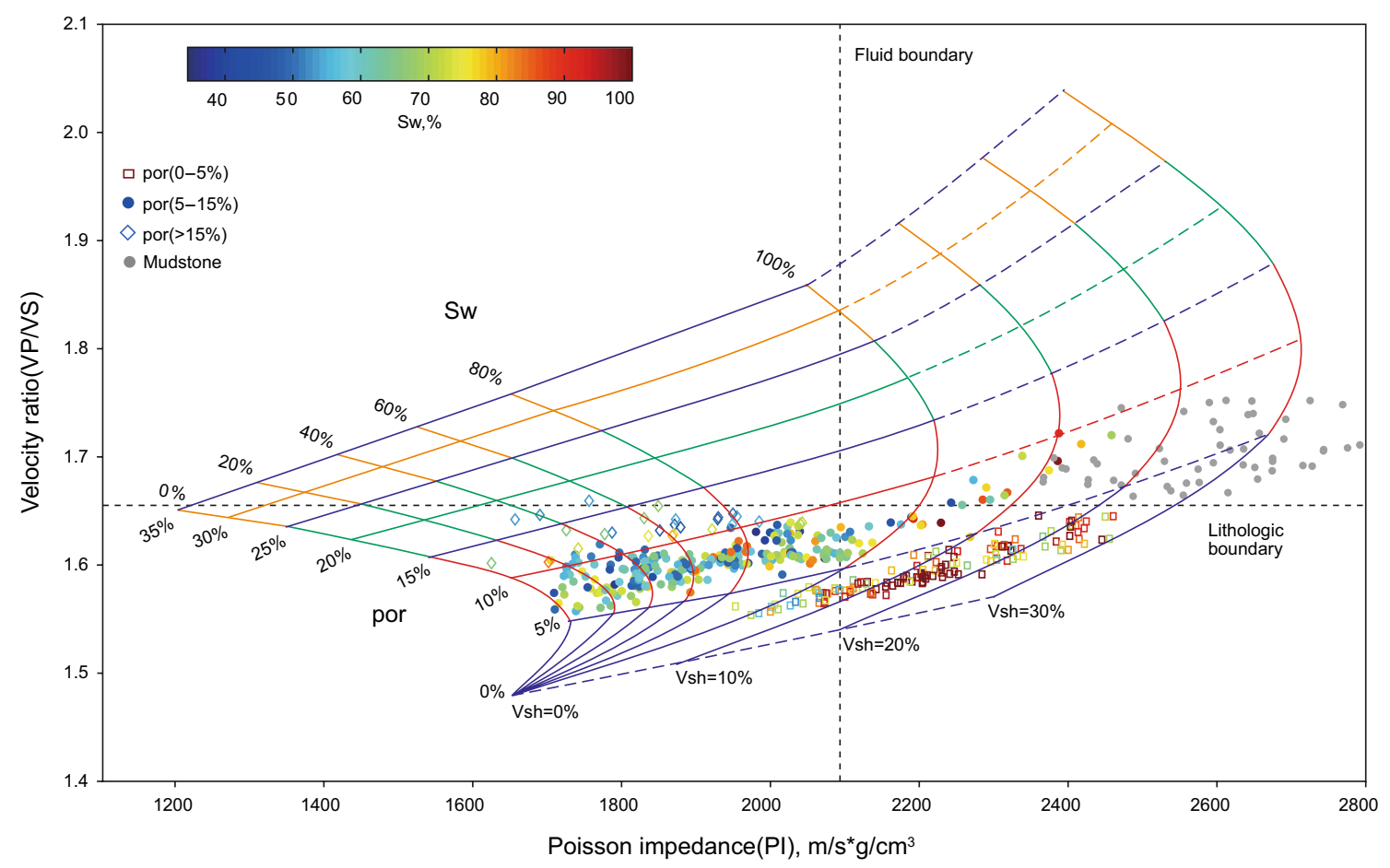

Fig. 4 Rock physics template of sweet spot and the real data application 
core permeability between A and B layers is large, and the permeability of A layer is generally greater than $1 \mathrm{md}$, with the maximum permeability even reaching $45 \mathrm{md}$, and the permeability of B layer is mainly concentrated in $0-3 \mathrm{md}$.

According to the Industry Standard of China's Tight Sandstone Gas (2011), the reservoir with porosity less than $10 \%$ and permeability less than $1 \mathrm{md}$ is defined as the tight sandstone reservoir (Zhang et al. 2017a, b). The reservoir background of target layers in the research area is mainly the tight sandstone reservoir, but develops relatively high-porosity and permeability-effective reservoirs, and the quality of reservoir in A layer is better than that in B layer obviously (Fig. 5a, b). Meanwhile, the statistical result of mineral composition reveals that the content of sandstone minerals in different wells and tectonic positions is almost the same (Fig. 5c), the content of quartz is about $66.1 \%-70.4 \%$, and that of potassium feldspar and anorthose is about $18.4 \%-22.7 \%$. The interstitial minerals are mainly authigenic minerals (such as calcite and dolomite) and argillaceous matrix, with the content of $9.3 \%-11.2 \%$.

\subsection{The pre-stack inversion of sweet spots}

Pre-stack seismic inversion is a feasible and effective way to obtain sensitive elastic parameters from pre-stack seismic data. To test the feasibility of the optimized elastic parameters for predicting sweet spot, five pre-stack angle gather data and five wells' logging data are used to invert velocity ratio and Poisson impedance.

Seismic wavelet will affect the accuracy of inversion results, and seismic wavelet optimization can be achieved by well-to-seismic calibration, so during the pre-stack inversion process, multi-round well-to-seismic calibration for five pre-stack angle gather data was carried out utilizing five

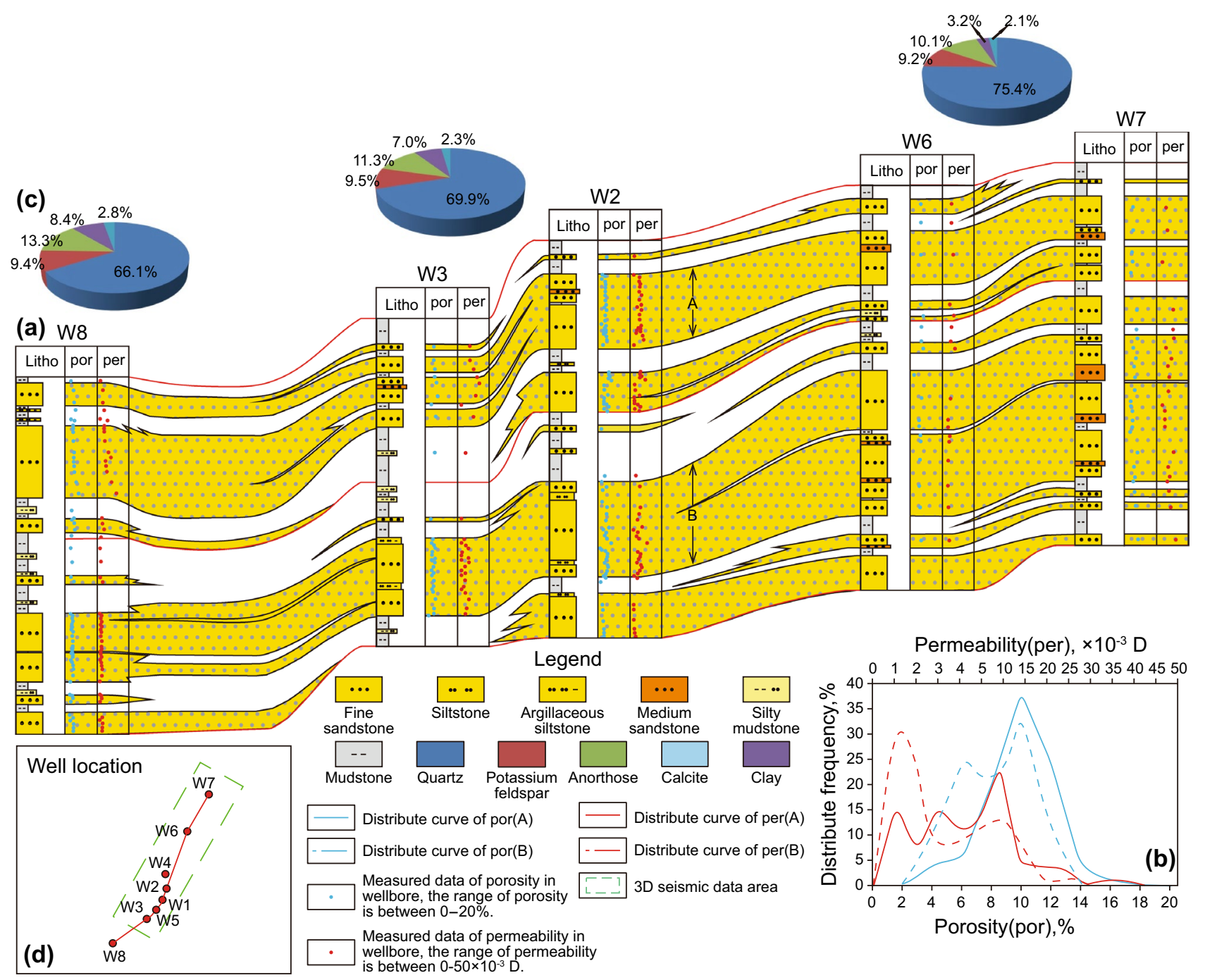

Fig. 5 Sandstone distribution and core porosity and permeability measured data among 5 wells (a) (see d for well location), statistical curves of porosity and permeability of A and B layers (b) and pie charts of mineral composition and content in different tectonic locations (c) 
well' logging data. For each pre-stack angle gather data, seismic wavelets from five wells were extracted firstly, and their synthetic records were fitted separately. Then by adjusting and comparing the matching relationships of seismic events between the actual seismic data and five synthetic seismograms constantly, the wavelets were determined, if the matching relationships were good. Otherwise, the above steps were repeated until the matching relationships were good. Finally, an average seismic wavelet was obtained by fitting multiple seismic wavelets from five pre-stack angle gather data, and this average seismic wavelet was introduced into the pre-stack inversion. On the basis of the workflow of the inversion method, the inversion results are shown in Figs. 6 and 7.

Figure 6 displays the inverted result of velocity ratio. The resolution of the inverted result is relatively high, and the reservoir and surrounding rock can be distinguished clearly. According to the color code, the red yellow color reflects the velocity ratio with the value lower than 1.65 and indicates the distribution of sandstone (Fig. 6a). Usually, the sandstone is characterized by low Gamma ray, and the Gamma value of sandstone is generally less than 80 API. The contrasts between the curves of Gamma ray (GR) and the well-side inversion results, and the logging interpretation results and velocity ratio plane map of layer $\mathrm{A}$ in different wells, show that the vertical and horizontal distributions of sandstone reflected by the velocity ratio and Gamma ray are almost the same (Fig. 6b, c).

As demonstrated from the rock physics template, the differences in the velocity ratio for the sweet spot and waterbearing sandstone are very small, which means that it is difficult to identify the fluid type through a simple application of the velocity ratio. The Poisson impedance can distinguish the sweet spot and water-bearing sandstone effectively. With the decrease in the value of Poisson impedance, the color changes from light blue to red. On the basis of the above elastic criterion of sweet spot, the Poisson impedance with the value lower than $2100 \mathrm{~m} / \mathrm{s} \mathrm{g} / \mathrm{cm}^{3}$ is mainly characterized as the red yellow color (Fig. 7a), and from the comparisons between the curves of porosity (por) and gas saturation $(\mathrm{Sg})$ and the well-side Poisson impedance inversion results, and the logging interpretation results and Poisson impedance plane map of layer A, the vertical and horizontal distributions of sweet spot reflected by the Poisson impedance and logging data are almost the same too, the more red the color is, the higher the porosity and gas saturation the reservoir is (Fig. 7b, c).

Meanwhile, the average well-side inversion results and average well calculation results of velocity ratio and Poisson impedance have been compared. The comparison results show that the errors between inversion results and calculation results of velocity ratio in different wells are generally less than 3\% (Fig. 8a), and the errors between

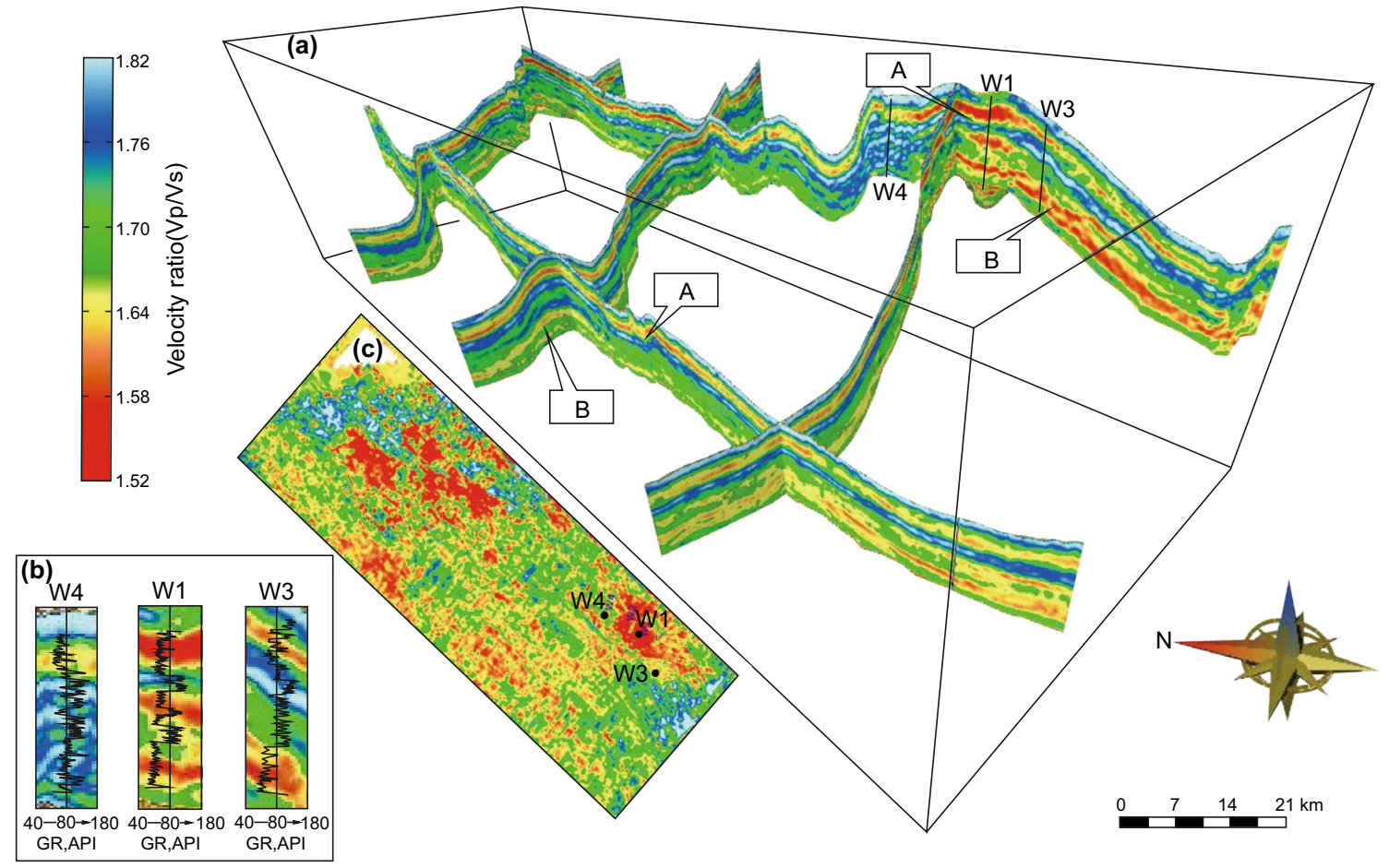

Fig. 6 Inversion results of velocity ratio (a), comparison between well-side inversion results and Gamma ray curves (b) and plane map of velocity ratio of target layer A (c) 


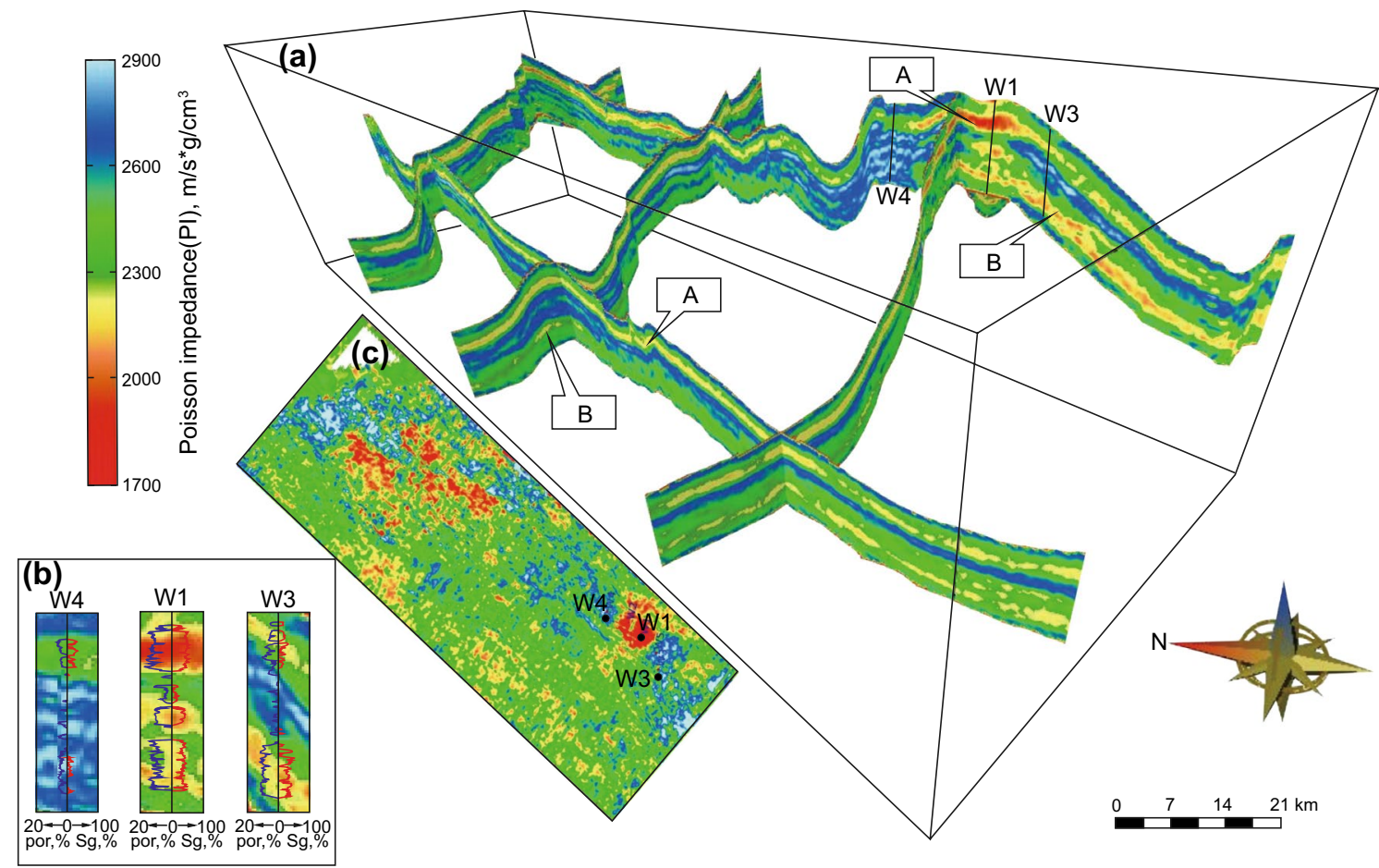

Fig. 7 Inversion results of Poisson impedance (a), comparison between well-side inversion results and porosity and gas saturation curves (b) and plane map of Poisson impedance of target layer A (c)

inversion results and calculation results of Poisson impedance are generally less than $2 \%$ (Fig. 8b), which further prove that velocity ratio and Poisson impedance can be used to reveal the lithologic and gas-bearing properties of sweet spots. Finally, the above real data applications have illustrated that the pre-stack seismic inversion method based on well-bore rock physical simulation can be used to predict the sweet spots in tight sandstone reservoirs.

\section{Discussions}

During the rock physical simulation processing, it is necessary to select appropriate models for rock physical simulation of tight sandstone. As the deep tight sandstone reservoirs developed in the East China Sea, the research degree of this tight sandstone reservoir is low, and pore structure data are not perfect, so Xu-White model, which is based on different pore structure and corresponding contents (Zhang et al. 2012a, b; Wang 2016; Jia et al. 2018),

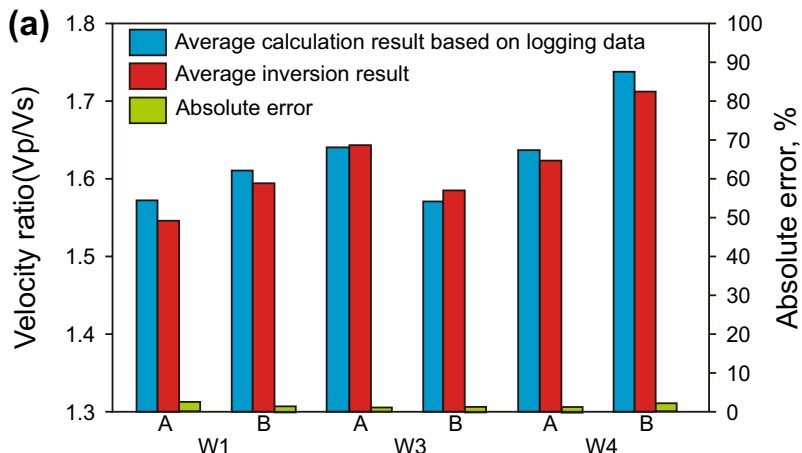

Wells and corresponding layers

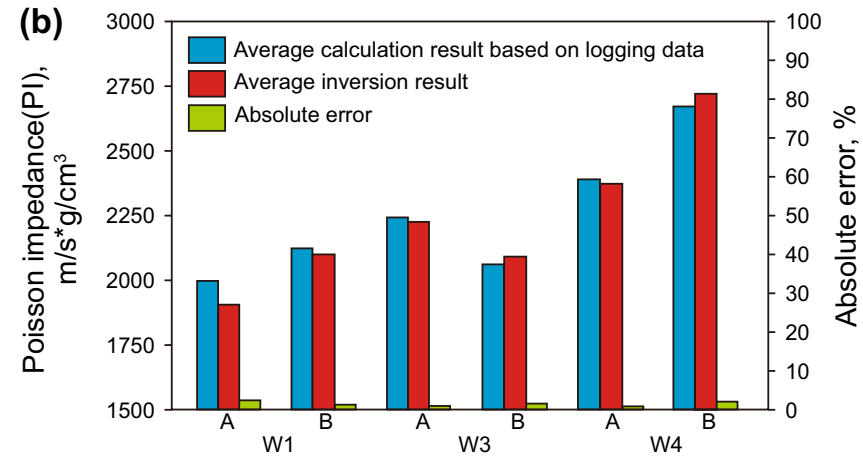

Wells and corresponding layers

Fig. 8 Comparison of average well-side inversion results and average well calculation results of velocity ratio (a) and Poisson impedance (b) 
cannot be utilized to simulate the elastic modulus of tight sandstone, while the rock consolidation parameter of Pride model can indicate the degree of consolidation among particles and the shape of voids formed among particles, and may reflect the pore structure to some extent (Pride 2005, Lee 2006). So Pride model is introduced in this paper, to solve the difficult of pore structure description. Take bulk modulus as an example, comparing the rock physical test results and bulk modulus curves of drained sandstone, Pride model with the rock consolidation parameter 7 can be used to simulate the elastic parameters of drained rock in test area (Fig. 9a). But follow-up with the deepening of the study of tight sandstone reservoirs in the East China $\mathrm{Sea}$, the Pride model can be replaced by $\mathrm{Xu}$-White model to obtain more accurate simulation results. For bulk modulus of pore-fluid simulation, Wood model gives the variation of bulk modulus with water saturation in saturated fluid state, while Patchy model is more suitable for pore fluid with non-uniform patchy distribution (Zhang et al. 2012a, b). But in actual geological situation, occurrence states of most pore fluids in tight reservoir are between saturated fluid state and non-uniform patchy distribution. So the weighted Wood and Patchy model is obtained by synthesizing the above two models to simulate the bulk modulus of pore fluid in tight sandstone reservoir. The real data distributions prove that the variation trend of bulk modulus with water saturation simulated by weighted Wood and Patchy model, with the weighted coefficient a between 0.4 and 0.6 , is close to that reflected by well interpretation results of test area (Fig. 9b). However, the occurrence state of pore fluid in tight sandstone reservoir is very complex in real situation. How to calculate the elastic parameters of low pore fluid accurately is still a difficult problem to be solved in rock physical simulation of tight sandstone reservoir.

From the rock physical simulation results of tight sandstone reservoir, we can see that Poisson impedance is more sensitive to gas-bearing property of tight reservoir than other elastic parameters, such as velocity ratio, lame constant, fluid factor. Statistical results of velocity and density in test area show that the variation regularity of $\mathrm{P}$ - and $\mathrm{S}$-wave velocities with lithology is poor, and the difference between sweet spot and water-bearing sandstone is small (Fig. 10a, b). While density can distinguish sweet spot and waterbearing sandstone well, the densities of most sweet spots are lower than that of water-bearing sandstone (Fig. 10c). Reflected in the elastic parameters, the velocity ratio lacks density parameters. Although lame constant and fluid factor involve density in the calculation processing, the difference between density and velocity is too large due to the square of $\mathrm{P}$ - and $\mathrm{S}$-wave velocities, which reduces the differentiation of density (Fig. 10d, e). In contrast, Poisson impedance is calculated from the multiplication of density and velocity difference, and the density strengthens its capacity to distinguish sweet spot from water-bearing sandstone and tight sandstone (Fig. 10f). In addition, the parameter $c$ of Poisson impedance can be calculated from the Greenberg-Castagna mudstone baseline equation according to the geological situation of actual area. By adjusting this parameter, Poisson impedance can satisfy the prediction of sweet spot in different research areas. Therefore, this paper considers that Poisson impedance has higher accuracy and wider applicability for sweet spot prediction of tight sandstone reservoirs.

As a widely used method for predicting sweet spot of tight sandstone reservoir, pre-stack seismic inversion needs the support of rock physical simulation in the inversion process.
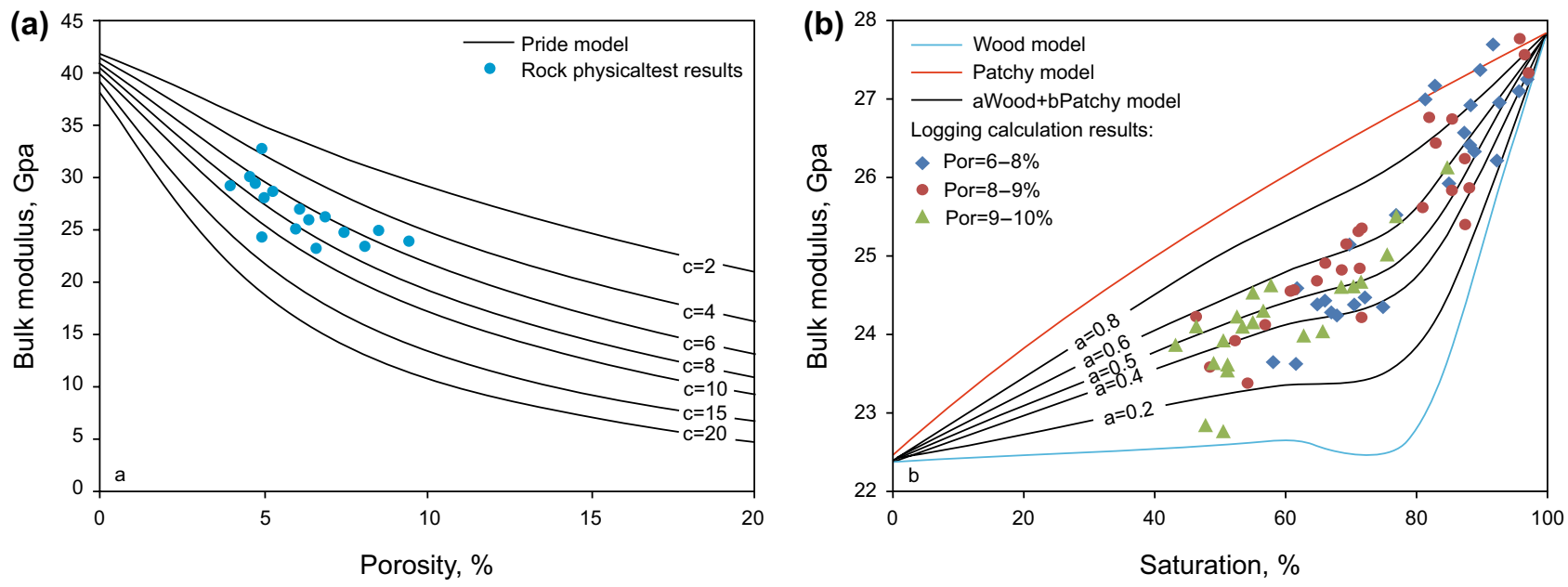

Fig. 9 Comparison and optimization of rock physical models of tight sandstone reservoir. a Bulk modulus of dry sandstone calculated by different rock consolidation parameters varied with porosity and the comparison of rock physical test results; b bulk modulus of saturated sandstone calculated by different models varied with saturation and the comparison of logging calculation results 

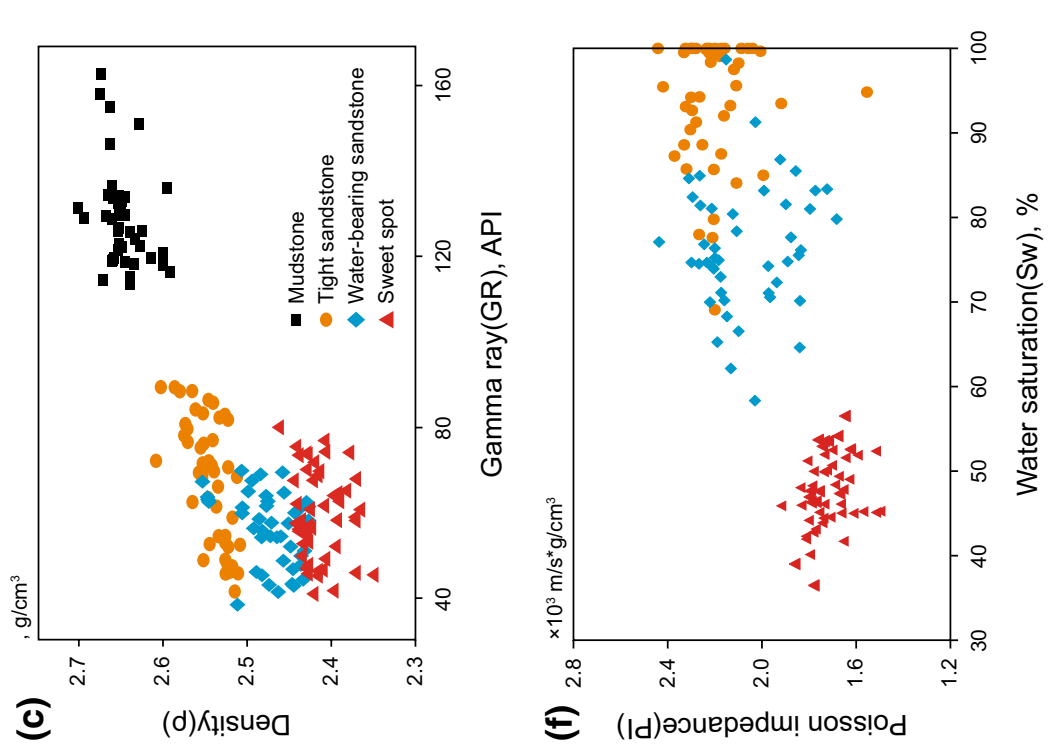

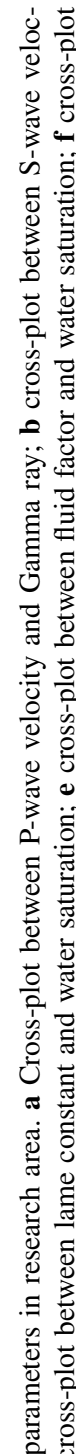
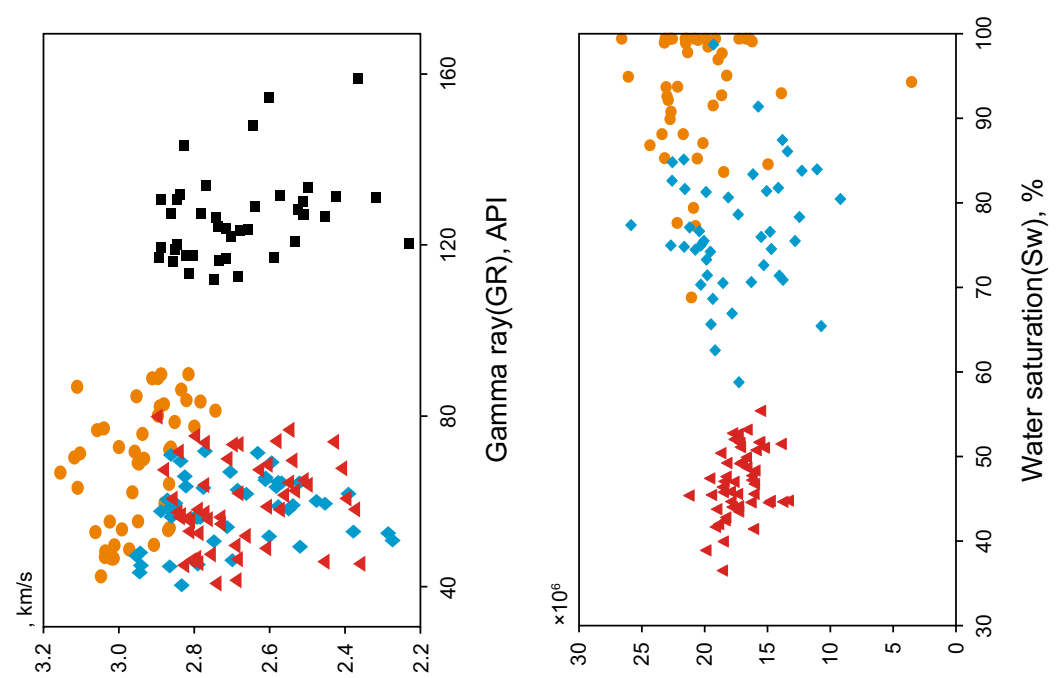

气 $\quad(\mathrm{s} \Lambda) \wedge !$ ํㅣㅅ әлем-s

()

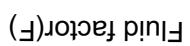
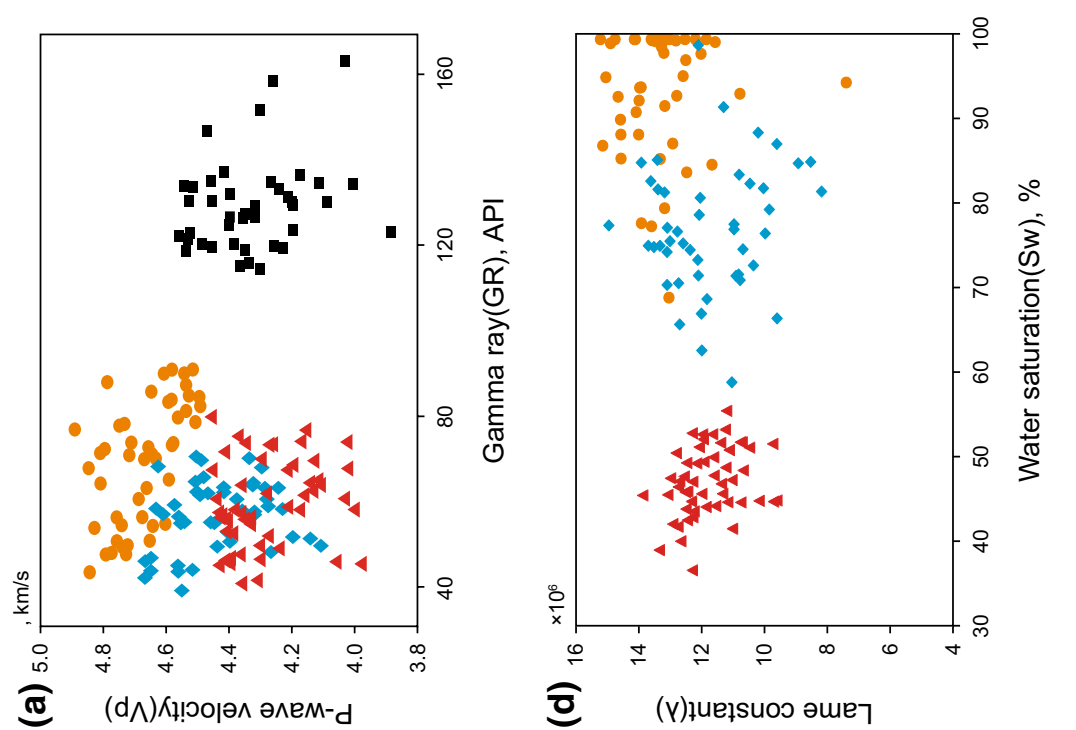

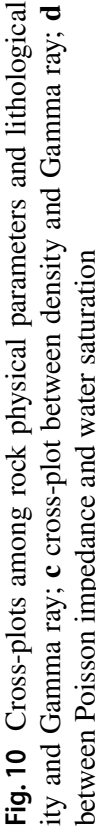


On the basis of rock physical forward modeling and simulation of tight sandstone reservoir, the most sensitive elastic parameters for identifying lithology and gas properties of the test area in this paper are velocity ratio and Poisson impedance, which has pointed out the inversion directions for pre-stack seismic inversion. Another important application of rock physical simulation is predicting S-wave velocity. During the pre-stack seismic inversion process, wells which are used to control inversion should contain P- and S-wave velocity, while W6 and W7 wells distributed in the north of the test area belong to old wells without S-wave velocity. So in the course of project research, the $S$-wave velocities of the above-mentioned wells are predicted by rock physical simulation and genetic algorithm, so as to provide constraints for pre-stack seismic inversion in this area. Restricted by the number of words in the article, this part of study is not in the article. Most importantly, a more effective rock physical criterion for sweet spot identification in test area is determined utilizing rock physical template. Relative to velocity and density, this rock physical criterion enhances the vertical resolution accuracy of logging interpretation, and guides the fine interpretation of seismic data, which can help construct a more precisely stratigraphic framework in inversion process and reduce the uncertainty of inversion. Generally speaking, with the help of well-bore rock physical simulation, pre-stack seismic inversion and interpretation of the test area may reach a new quantitative or semiquantitative level from traditional qualitative interpretation.

\section{Conclusions}

Five rock models and three well-bore rock physical models are built after supposing parameters such as mineral components, porosity, pore-fluid type and saturation. Then, the relationship between lithology and elastic parameters is clarified by using the rock physical simulation method of tight reservoir. Generally speaking, velocity ratio and Poisson impedance is the best elastic parameter pair to reveal the lithologic and gas properties of sweet spot. Although the velocity ratio of high-porosity water-bearing sandstone is larger than that of mudstone, it can still be used to distinguish most of sandstone. Poisson impedance can distinguish sweet spot from water-bearing sandstone effectively and changes regularly with the varied porosity and gas saturation. Sweet spot is mainly characterized by the low velocity ratio and Poisson impedance.

Considering the influences of shale content, porosity, fluid type and saturation comprehensively, the rock physics template is constructed and the elastic criterion for predicting the lithologic and gas-bearing properties of sweet spot is determined. The sweet spot in test area can be defined as the tight sandstone reservoir with velocity ratio lower than
1.67 and Poisson impedance lower than $2100 \mathrm{~m} / \mathrm{s} \mathrm{g} / \mathrm{cm}^{3}$. The comparison between the log curves and corresponding geophysical parameters in different wells and the well-side inversion results implies that velocity ratio indicates the distribution of sandstone accurately, and Poisson impedance is the best indicator to predict the sweet spot in tight sandstone reservoir, which proves that the comprehensive utilization of well-bore rock physical simulation and pre-stack seismic inversion can predict the sweet spot of tight sandstone reservoir effectively.

The well-bore forward simulation results of this paper prove that the conclusion that low velocity ratio and low Poisson impedance can effectively characterize dessert of tight sandstone reservoir is correct. Then combined with the actual geological conditions of research area, the thresholds of velocity ratio and Poisson impedance have been determined further, providing a theoretical basis for semiquantitative or quantitative interpretation of inversion results. In addition, this paper can also provide a research idea and method for sweet spot prediction of other small fault basins with similar geological conditions in eastern China. It should be noted that the optimization of sensitive elastic parameters of sweet spot and its thresholds should be depending on the actual geological conditions of different research areas.

Acknowledgements The authors would like to thank the editors and reviewers for their valuable comments. This work is supported by the National Key R\&D Program of China (Grant No. 2018YFC1405900), the Major Projects of National Science and Technology (Grant Nos. 2016ZX05011-002, 2016ZX05027-002-005), the National Natural Science Foundation of China (Grant No. 41806073), the Natural Science Foundation of Shandong Province (Grant No. ZR2017BD014), Shandong Provincial Key Laboratory of Depositional Mineralization and Sedimentary Minerals, Shandong University of Science and Technology (Grant No. DMSM2017042) and the Fundamental Research Funds for the Central Universities (Grant No. 201964016).

Open Access This article is distributed under the terms of the Creative Commons Attribution 4.0 International License (http://creativeco mmons.org/licenses/by/4.0/), which permits unrestricted use, distribution, and reproduction in any medium, provided you give appropriate credit to the original author(s) and the source, provide a link to the Creative Commons license, and indicate if changes were made.

\section{References}

Ahmed N, Khalid P, Ghazi S, et al. AVO forward modeling and attributes analysis for fluid's identification: a case study. Acta Geod Geophys. 2015;50(4):377-90. https://doi.org/10.1007/s4032 8-014-0097-x.

Ahmed N, Khalid P, Anwar AW. Rock physics modeling to assess the impact of spatial distribution pattern of pore fluid and clay contents on acoustic signatures of partially-saturated reservoirs. Acta Geod Geophys. 2016;51(1):1-13. https://doi.org/10.1007/s4032 8-015-0101-0.

Albrecht D, Reitenbach V. Laboratory measurements of fluid transport properties on tight gas sandstones and applications. Energy 
Procedia. 2014;59:366-73. https://doi.org/10.1016/j.egypr o.2014.10.390.

Amiri M, Zahedi G, Yuan MH. Reducing predictive uncertainty in log-derived water saturation models in a giant tight sandstones: a case study from Mesaverde tight gas reservoir. J Nat Gas Sci Eng. 2015;23:380-6. https://doi.org/10.1016/j.jngse.2015.01.040.

Bachrach R. Joint estimation of porosity and saturation using stochastic rock-physics modeling. Geophysics. 2006;71(5):53-63. https:// doi.org/10.1190/1.2235991.

Berryman JG. Mixture theories for rock properties handbook of physical constants. New York: American Geophysical Union; 1995. p. 205-28.

Berryman JG, Berge PA, Bonner BP. Estimating rock porosity and fluid saturation using only seismic velocities. Geophysics. 2002;67(2):391-404. https://doi.org/10.1190/1.1468599.

Bosch M, Mukerji T, Gonzalez EF. Seismic inversion for reservoir properties combining statistical rock physics and geostatistics: a review. Geophysics. 2010;75(5):75A165-76. https://doi. org/10.1190/1.3478209.

Chen S, Wang S, Zhang Y, et al. Reservoir prediction using pre-stack inverted elastic parameters. Appl Geophys. 2009;6(4):349-58. https://doi.org/10.1007/s11770-009-0035-9.

Cudjoe S, Vinassa M, Gomes JHB, et al. A comprehensive approach to sweet-spot mapping for hydraulic fracturing and $\mathrm{CO}_{2}$, huff-npuff injection in Chattanooga shale formation. J Nat Gas Sci Eng. 2016;33:1201-18. https://doi.org/10.1016/j.jngse.2016.03.042.

Dai JX, Ni YY, Gong DY, et al. Geochemical characteristics of gases from the largest tight sand gas field (Sulige) and shale gas field (Fuling) in China. Mar Pet Geol. 2017;79:426-38. https://doi. org/10.1016/j.marpetgeo.2016.10.021.

Ehsan MI, Ahmed N, Khalid P, et al. An application of rock physics modeling to quantify the seismic response of gas hydrate-bearing sediments in Makran accretionary prism, offshore, Pakistan. Geosci J. 2016;20(3):321-30. https://doi.org/10.1007/s1230 3-015-0044-z.

Feng H, Bancroft JC, Russell BH. A comparison of hydrocarbon indicators derived from AVO analysis. In: SEG technical program expanded abstracts, vol. 1; 2007. p. 3124. https://doi. org/10.1190/1.2792426.

Gassmann F. Elastic waves through a packing of spheres. Geophysics. 1951;16(4):673-85. https://doi.org/10.1190/1.1437718.

Hart BS. Channel detection in 3-D seismic data using sweetness. AAPG Bull. 2008;92(6):733-42. https://doi.org/10.1306/02050 807127.

He FB, You J, Chen KY. Gas sand distribution prediction by pre-stack elastic inversion based on rock physics modeling and analysis. Appl Geophys. 2011;8(3):197-205. https://doi.org/10.1007/s1177 0-011-0285-1.

Hyndman RD, Spence GD. A seismic study of methane hydrate marine bottom simulating reflectors. J Geophys Res. 1992;97(B5):668398. https://doi.org/10.1029/92jb00234.

Jakobsen M, Hudson JA, Minshull TA, et al. Elastic properties of hydrate-bearing sediments using effective medium theory. J Geophys Res. 2000;105(B1):561-77. https://doi.org/10.1029/1999j b900190.

Jia LY, Li L, Wang QY, et al. Optimization of the rock physical model in tight sandstone reservoir. Adv Earth Sci. 2018;33(4):416-24. https://doi.org/10.11867/j.issn.1001-8166.2018.04.0416 (in Chinese).

Khalid P, Ghazi S. Discrimination of fizz water and gas reservoir by AVO analysis: a modified approach. Acta Geod Geophys. 2013;48(3):347-61. https://doi.org/10.1007/s40328-013-0023-7.

Khalid P, Broseta D, Nichita DV, et al. A modified rock physics model for analysis of seismic signatures of low gas-saturated rocks. Arab J Geosci. 2014;7(8):3281-95. https://doi.org/10.1007/s1251 7-013-1024-0.
Khalid P, Ahmed N, Khan KA, et al. AVO-derived attributes to differentiate reservoir facies from non-reservoirs facies and fluid discrimination in Penobscot area, Nova Scotia. Geosci J. 2015;19(3):471-80. https://doi.org/10.1007/s12303-014-0048-0.

Lee MW. A simple method of predicting S-wave velocity. Geophysics. 2006;71(6):161-4. https://doi.org/10.1190/1.2357833.

Mavko G, Mukerji T. Bounds on low-frequency seismic velocities in partially saturated rocks. Geophysics. 1998;63(3):918-24. https ://doi.org/10.1190/1.1444402.

Mollajan A, Mehrgini B, Memarian H. A fusion approach to identify reservoir facies based on rock physics modeling. Arab J Geosci. 2015;8(11):9531-43. https://doi.org/10.1007/s1251 7-015-1849-9.

Pei FG, Zou CC, He T, et al. Fluid sensitivity study of elastic parameters in low-medium porosity and permeability reservoir rocks. Appl Geophys. 2010;7(1):1-9. https://doi.org/10.1007/s1177 0-010-0005-2.

Pride SR. Relationships between seismic and hydrological properties. Hydrogeophysics. 2005;50:253-90. https://doi. org/10.1007/1-4020-3102-5_9.

Pride SR, Berryman JG, Harris JM. Seismic attenuation due to waveinduced flow. J Geophys Res. 2004;109(B1):59-70. https://doi. org/10.1029/2003JB002639.

Qian WD, Yin TJ, Hou GW. A new method for clastic reservoir prediction based on numerical simulation of diagenesis: a case study of the ED1 clastic sandstones in the Bozhong depression, Bohai Bay Basin, China. Adv Geo Energy Res. 2019;3(1):82-93. https://doi. org/10.26804/ager.2019.01.07 (in Chinese).

Quakenbush M, Shang B, Tuttle C. Poisson impedance. Lead Edge. 2006;25(2):128-38. https://doi.org/10.1190/1.2172301.

Russell BH, Hedlin K, Hilterman FJ, et al. Fluid property discrimination with AVO: a Biot-Gassmann perspective. Geophysics. 2003;68(1):29-39. https://doi.org/10.1190/1.1543192.

Sena A, Castillo G, Chesser K, et al. Seismic reservoir characterization in resource shale plays: Sweet spot discrimination and optimization of horizontal well placement. In: SEG technical program expanded; 2011. p. 1744-8.

Sengupta M, Bachrach R. Uncertainty in seismic-based pay volume estimation: analysis using rock physics and Bayesian statistics. Lead Edge. 2007;26(2):184-9. https://doi.org/10.1190/1.2542449.

Sharma RK, Chopra S. Identification of sweet spots in shale reservoir formations. Tech Artic. 2016;34:39-47.

Shuey RT. A simplication of the Zoeppritz equations. Geophysics. 1985;50(4):609-14. https://doi.org/10.1190/1.1441936.

Si WP, Di BR, Wei JX. Seismic physical modeling and gas saturation prediction of partially-saturated gas sand reservoir. Chin J Geophys. 2017;60(4):1547-56. https://doi.org/10.6038/cjg2017042 7 (in Chinese).

Wang DX. Study on the rock physics model of gas reservoirs in tight sandstone. Chin J Geophys. 2016;59(12):4603-22. https://doi. org/10.6038/cjg20161222 (in Chinese).

$\mathrm{Xu}$ SY, White RE. A new velocity model for clay-sand mixtures. Geophys Prospect. 1995;43(1):91-118. https://doi. org/10.1111/j.1365-2478.1995.tb00126.x.

Yang SY, Zhang JC, Huang WD, et al. Sweet spot types of reservoirs and genesis of tight sandstone gas in Kekaya area, Turpan-Hami Basin. Acta Pet Sin. 2013;34(2):272-82. https://doi.org/10.7623/ syxb201302009 (in Chinese).

Yin XY, Zong ZY, Wu GC. Research on seismic fluid identification driven by rock physics. Sci China Earth China. 2015;58(2):159_ 71. https://doi.org/10.1007/s11430-014-4992-3.

Zhang JJ, Li HB, Yao FC. Rock critical porosity inversion and S-wave velocity prediction. Appl Geophys. 2012a;9(1):57-64. https://doi. org/10.1007/s11770-012-0314-8.

Zhang JQ, Ma ZG, Qu SL, et al. Calculation of volume modulus of mixed phase fluid in carbonate reservoir fluid replacement. 
Geophys Prospect Pet. 2012b;51(2):133-7. https://doi. org/10.3969/j.issn.1000-1441.2012.02.004 (in Chinese).

Zhang LQ, Zhang HX, Jiang XD, et al. Application of elastic parameters inversion and attribute fusion technology in the "sweet spot" prediction. Nat Gas Geosci. 2017a;28(4):582-9. https://doi. org/10.11764/j.issn.1672-1926.2017.03.004 (in Chinese).

Zhang S, Huang HD, Li HJ, et al. Pre-stack seismic facies-controlled joint inversion of reservoir elastic and petro-physical parameters for sweet spot prediction. Energy Explor Exploit. 2017b;35(6):767-91. https://doi.org/10.1177/0144598717716286.

Zheng L, Chen C, Lu C, et al. Study on facies-controlled model of a reservoir in Xi-jiang 24-3 oilfield in the Northern Pearl River
Mouth Basin. Adv Geo Energy Res. 2018;2(3):282-91. https:// doi.org/10.26804/ager.2018.03.06.

Zong ZY, Yin XY, Wu GC. Frequency dependent elastic impedance inversion for interstratified dispersive elastic parameters. J Appl Geophys. 2016;131:84-93. https://doi.org/10.1016/j.jappg eo.2016.05.010.

Zou CN, Zhao Q, Zhang G, et al. Energy revolution: from a fossil energy era to a new energy era. Nat Gas Ind B. 2016;3(1):1-11. https://doi.org/10.1016/j.ngib.2016.02.001. 